\title{
THE “ANALGIZER” IN A GENERAL HOSPITAL: A PRELIMINARY REPORT*
}

\author{
A. Romagnoli, M.D., L. Busque, M.D., ANd David J. Power, M.D., F.R.C.P.(c)
}

IT Is Now beyond doubt that methoxyflurane is a powerful, useful, and safe analgesic. More than one type of apparatus has been tested for the inhalation of analgesic vapours of methoxyflurane and all were found effective, provided the concentration was maintained between 0.8 and 0.4 per cent with slight variations allowed on either side. ${ }^{1-B}$

Because the concentration inhaled was so low, there were never any detrimental effects reported in the literature on the progress of labour or on the wellbeing of the foetus immediately before or immediately after birth, while on the other hand, a favourable effect was detected on the relief of pain. . $^{6-9}$

Lately, a disposable inhaler has been marketed by Abbott Laboratories under the name of the Analgizer. This new device, designed for self-administration of methoxyflurane vapour in air, is made up of a polyethylene cylinder 5/4 inches in length and 1 inch in diameter; a mouthpiece 1 inch long increases the length. Within it, there is a rolled wick of polypropylene felt held in place by small ribs and by its own springiness. This holds $15 \mathrm{cc}$ of methoxyflurane. The "cigar," as this apparatus was quickly renamed in our hospital (adding to its popularity), can be used alone or with an anaesthetic mask slipped onto it. The plastic is of high density and is not affected by methoxyflurane over a short period of time.

Its use is quite simple and the patient has no difficulty in adapting to it and appreciating its effectiveness. To prevent premature exhaustion of the charge, which should last for two to three hours, and also to prevent lowering of the vapour concentration by avoiding water-vapour accumulation in the wick, patients should not exhale through the Analgizer. The patient should be lying down comfortably. It should be noted that other analgesics may have a cumulative effect.

This apparatus was tested by us for delivery of concentration, and our findings support the ones presented by the company with a plus or minus variation of 0.1 per cent. However, we also tested these deliveries using a 14 litre/minute flow $^{2}$ for 45 seconds, at three-minute intervals, keeping the Analgizer at hand temperature for the whole period so as to reproduce the clinical situation as closely as possible. We found that here too the delivered concentration was in keeping with published results.

Because of the simplicity of the Analgizer and the physical and pharmacological characteristics of methoxyflurane, it was very easy and very pleasant for all types of patients to self-administer the vapour and quickly achieve a level of

'From the Department of Anaesthesia, Ottawa General Hospital. Supplies of the Analgizers and methoxyflurane (Penthrane) were kindly provided by Abbott Laboratories Ltd., Montreal. 
conscious analgesia which could be maintained on demand over a long period of time. During this stage of conscious analgesia, the patient is often partly amnesic to the sense of pain; at other times, he is fully aware of a sensation of pain but feels separated from it, though he may or may not react to it at will. Sometimes, it was noted at this stage, that a tendency toward over-confidence and garrulousness could develop. However, either the treatment was acceptable to the patient and therefore successful clinically, or it could not continue.

We began our study in the obstetrical ward: 72 cases were good, 11 cases fair, and 10 cases poor. Eighteen did not receive any other analgesic drug; these cases were equally distributed among the three groups. The duration varied from a minimum of fifteen minutes to a maximum of four hours. Naturally, those patients who did not like either the odour or the effect received the shortest administration. We obtained the results by objective and subjective evaluation. A standard set of questions was answered by both the medical attendant and the patient herself. Of the failures, nine refused to accept it on the basis of unpleasant odour, and one patient became very agitated. The average duration was 79 minutes. The Apgar scores were judged by both the obstetrician and the anaesthesiologist as being quite comparable to those obtained when patients did not use the Analgizer. There were four cases of low scores, which could be accounted for by prematurity or other reasons independent of our study.

The results of this series of obstetrical patients showed that 77.4 per cent of the administrations were successful from an analgesic and clinical point of view. This is supported by Jones et al., ${ }^{6,7}$ and Rosen et al., ${ }^{8}$ who mention much the same results using similar concentrations of the same agent but employing a different apparatus. Eleven and seven-tenths per cent were fair and 10.6 per cent were total failures. They were scored by the attendant and by the patient herself.

Study of a second group of patients was begun in the emergency department and includes to date eleven cases of fractures and dislocations awaiting treatment. The duration was from a minimum of 15 minutes to a maximum of two hours, with an average duration of 54 minutes. Four of these patients did not receive any other analgesic drug. Three cases were failures, of which one patient vomited and the other two were unco-operative. Seventy-two per cent were successes.

\section{Discussion}

A previous report of this disposable inhaler ${ }^{10}$ covered only fourteen cases, and the authors correlated maternal and foetal blood gas analyses. They concluded that there was no evidence of abnormal parameters in any of the cases, and this conclusion compared quite closely with that reached in other studies. We did not attempt in any way to correlate our results with any measurements or determination of any biological functions. Our experience and that of others has repeatedly shown that the concentrations of methoxyflurane used for analgesic purposes are so low that they cannot and do not affect any of the body functions. We concur with Jones et al. ${ }^{9}$ that methoxyflurane induces a placid state in most mothers without abolishing their co-operation. However, overdosage most often produced drowsiness and occasionally restlessness. Nausea and vomiting was not experi- 
enced, but the odour, contrary to the experience of Jones et al., ${ }^{10}$ did account for some of our failures because the administration could not be continued. Our evaluation was based entirely on the objective judgement of the nurse and physician in attendance, as well as the subjective opinion of the patient, obtained by questioning during and after the inhalation of the vapour. The nurses in attendance were in favour of this technique, as Rosen et al. ${ }^{11}$ report, but closer supervision was required.

\section{SUMMARY}

We found the advantages of the Analgizer to be the following:

1. It is simple to administer.

2. It produces a high percentage of satisfactory results (i.e. 80 per cent in our study).

3. It may be given to several patients simultaneously.

4. It allows labour to progress normally.

5. All vital signs remained normal in the mother, the baby, or the injured patient.

6. It is disposable, thus preventing the risk of cross infection and eliminating the need for cleaning and sterilization.

7. It is safe over a prolonged period of time.

8. The patient, after a brief explanation, takes to it quite readily.

The disadvantages were:

1. The unpleasant and nauseating odour.

2. A feeling of over-confidence on the part of the patient during the analgesic stage, which required constant supervision of the nurses.

3. The high price. Each administration costs $\$ 3.50$ ( $\$ 1.10$ for the Analgizer and $\$ 2.40$ for each $15 \mathrm{cc}$ dose of methoxyflurane). This lasts for less than two hours, after which a further dose of methoxyflurane is needed.

To conclude, we liked the Analgizer because of its safety, effectiveness, and simplicity. Its greatest drawbacks were its high cost and the necessity of having a nurse in constant attendance during its administration. We intend to expand its use to other areas such as the dressing of wounds on surgical wards and for minor diagnostic procedures in urology.

\section{ACKNOWLEDGMENTS}

We gratefully acknowledge the co-operation of the departments of obstetrics, surgery, and urology, without which this work would not have been possible.

\section{REFERENCES}

1. Boisvert, M. \& Hudon, F. Clinical Evaluation of Methoxyflurane in Obstetrical Anaesthesia: A Report on 500 Cases. Canad. Anaesth. Soc. J. 9: 325 (1962).

2. Romagnoli, A. \& Korman, D. Methoxyflurane in Obstetrical Anaesthesia and Analgesia. Canad. Anaesth. Soc. J. 9: 414 (1962).

3. Schubert, F. \& Keuter, J. R. Experience with Methoxyflurane in Obstetrical Anaesthesia. Third World Congress of Anaesthesiologists, Sao Paulo, Brazil. Vol. II (1964), pp. 25-27. 
4. Kortss, H. I.; Saver, L. E.; Setrzman, L.; \& Fleiscaer, J. A Clinical Evaluation of Selfadministered Methoxyflurane Analgesia in Labor. J. Newark Beth Israel Hospital. 18: 79 (1967).

5. Cosmi, E. V. \& MArx, G. F. Acid-base Status and Clinical Condition of Mother and Foetus Following Methoxyflurane Anaesthesia for Vaginal Delivery. Brit. J. Anaesth. 40:94 (1968).

9. Lorhan, P. H. \& Giman, J. The Obstetric Patient as an Anaesthetic Problem, Anesth. \& Analg, 41: 686 (1962).

10. MarX, G. F.; Chen, L. K.; \& Tabora, J. A. Experiences with a Disposable Inhaler for Methoxytlurane Analgesia during Labour: Clinical and Biochemical Results. Canad. Anaesth. Soc. J. 16: 1 (1969).

6. Jones, P. L.; Rosen, M.; Mushin, W. W.; \& Jones, E. V. Methoxyflurane and Nitrous Oxide as Obstetric Analgesics: 1. A Comparison by Continuous Administration. Brit. Med. J. 3: 255 (1969).

7. Jones, P. L.; Rosen, M.; Mushn, W. W.; \& Jones, E. V. Methoxyflurane and Nitrous Oxide as Obstetric Analgesics: 2. A Comparison by Self-administered Intermittent Inhalation. Brit. Med. J. 3: 259 (1969).

8. Rosen, M.; Mushin, W. W.; Jones, P. L. \& Jones, E. V. Field Trial of Methoxyflurane, Nitrous Oxide, and Trichloroethylene as Obstetric Analgesics. Brit. Med. J. 3: 263 (1969). 